\title{
Internet of Things based Street Lighting Automation Vehicle Speed and Counting System for Highways
}

\author{
Vallala Alekya, L. M .I. Leo Joseph
}

\begin{abstract}
Saving energy is a major factor for a day now. Prevention of accidents using the most advanced technology. Speed and counting method of highways in the emerging Internet system of things focused on street lighting automation. We also implemented an automatically turned on and off feature that relies on light intensity, vehicle presence sensor and number system. This proposed system, integrated into the system's efficient auto intensity monitoring system-light, accidents control and speed inspection system, is all monitored on the Internet for quick data transmission and response.
\end{abstract}

\section{Index Term: IOT,IR, LDR, ARDUINO.}

\section{INTRODUCTION}

A road light controller with various sensors and wireless modules should be installed on the polar light. The road lighting device on the streetlight poles monitors the road illumination of LEDs, and transmitting data between street lighting, based on traffic flow. Wireless infrastructure is used for the management of the network for transmission of the data from the street light controller to base station[1]. The system can be used automatically and manually for the operation mode. When necessary the control system switches on the lights and may also change the intensity of the street light as required. The Web of Everything, after it arrives, is really an integral and valuable part of our daily existence. It shows significant changes over traditional systems and other traditional household equipment to enhance our lives[ 5-10]. IoT is simply an organizational (OT) and IT mix that helps the computer to interpret data in order to gain understanding.

\section{LITERATURE OVERVIEW}

$\operatorname{In}[2]$ this article focuses on the need for automatic street lighting and the special way in which embedded system devices are carried out. The piezo electric sensor is used in this system for detecting the movement of the object on the street rather than using the IR sensor. This paper provides a solution for the control of light intensity in view of road

Manuscript received on December 10, 2020.

Revised Manuscript received on December 20, 2020.

Manuscript published on January 30, 2020.

* Correspondence Author

Vallala Alekya*, Pursuing master of technology in Electronic Design Technology, S R Engineering College,Warangal.

Dr. L.M.I. Leo Joseph working as Assistant Professor in department of Electronics and Communication Engineering, S R Engineering College, Warangal, Telangana.

(C) The Authors. Published by Blue Eyes Intelligence Engineering and Sciences Publication (BEIESP). This is an open access article under the CC-BY-NC-ND license http://creativecommons.org/licenses/by-nc-nd/4.0/ movement. In[3] the program seeks to recognise the activity of the cars on the roads to turn on just one block in front and switch off the trailing light in order to conserve electricity. In[ 3 ] this scheme is planned During the night, all the lights on the highways stay $\mathrm{ON}$ for the vehicle, but a lot of energy is lost if the roads do not move. Two forms of sensors, light sensor, electrical camera sensor were used in this article. In[ 4] Automatic Street Light Control System, the strong strategy is not only the simplest. In this method, Relay utilizes an adaptive transition. It distributes up to $100 \%$ manual work. When the sun goes under our skin's visible area, it immediately triggers light. The Light Dependent Resistor (LDR) is a form of sensor that functions and detects the light, like our eyes are doing. Once the sun comes, it automatically turns OFF lights into visible light in our eyes. Such a device is also beneficial for energy consumption control.

\section{EXISTING SYSTEM}

In the existing highway light system every day, ON / OFFs are turned by hand and there is no energy consumption saving waste no flow, no energy-efficient devices. The whole circuit is wired with essentially no monitoring system for alerts

\section{PROPOSED SYSTEM}

The proposed street lighting automation system for roads is fully automated, using a LDR sensor, which recognizes the lights that light can be dim and brighter. LDR sensors detect the light intensity. The vehicle number and speed control feature of this device is also tracking these aspects via IoT. Sends server data. The suggested architecture provides an engineering and server management IoT communication system for outstanding platform and information exchange. Which ensures which intelligent street light is remotely monitored and roboted. This advanced system measures speed, count, intensity of light, all transmitted data to IoT and automatically controls the corresponding sensor.

\section{METHODOLOGY}

In order to find the perfect solution for power loss on highways, the proposed smart lighting system is designed. IoT technology is implemented by means of an Androiden device, a MCU, sensors to measure different parameters and a light, speed and vehicle count. The Light Sensor detects the amount of light, the IR sensor that receives information, count and speed that is given to the micro control system interface. 
All sensors monitor the status in LCD and transmit the data via the IoT server. The Light automatically lightens and dims in dependence on the IR status.

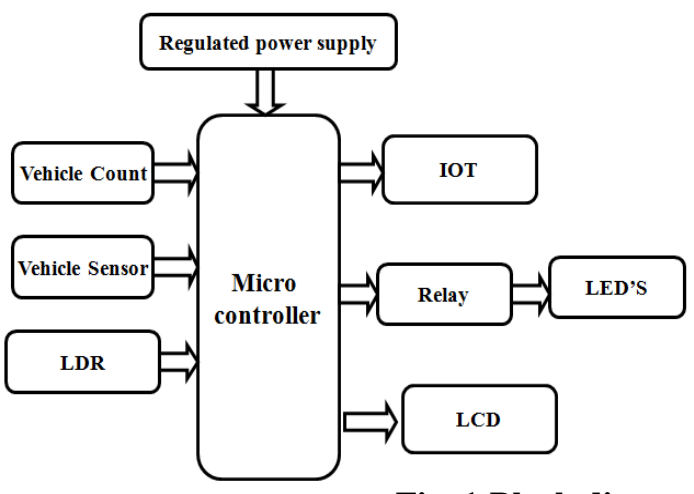

Fig. 1.Block diagram

\section{FUNCTIONAL DESCRIPTION}

\section{A. Regulated Power Supply}

This is the small power supply circuit controlled by $+5 \mathrm{~V}$. We have used 7805 Voltage Regulator IC for all things considered here. 7805 is the $78 x x$ family +5 Volt IC controller. The circuit has a limit on internal current and warm warm insurance.

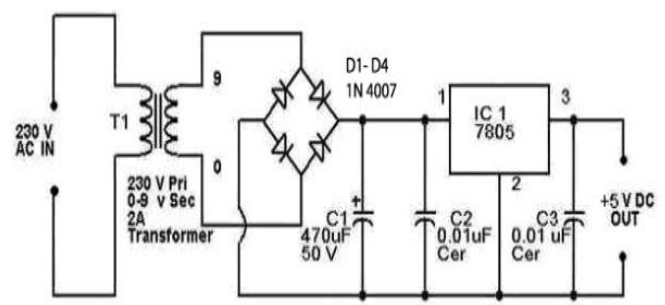

Fig. 2.Power supply

To protect $230 \mathrm{~V}$ to $9 \mathrm{~V}$ from mains, a phase down transformer $9 \mathrm{~V} 2 \mathrm{~A}$ is used. The scaffold rectifier was used here for transforming the AC-DC consisting of four $1 \mathrm{~N} 4007$ diodes. To separation purposes $470 \mathrm{uF} 50 \mathrm{v}$ as $\mathrm{C} 1$ is used. This circuit is extremely easy to build. $8 \mathrm{~V}-18 \mathrm{~V}$ information voltage is needed for good performance. Should the power requirement be over $400 \mathrm{~mA}$, a warmth sink with the $7805 \mathrm{IC}$ will be used at that time.

\section{B. ARDUINO Microcontroller}

We use ARDUINO microcontroller to design the proposed system, as input and output interfaces as well as processing units. Arduino uno has 28 pins that are classified as D0 to D13 digital and analog pins. Remote ports are linked to all digital sensors. All analog sensors are connected to analog port from A0 to A5. The 8-bit microcontroller has a memory of $32 \mathrm{~kb}$ for processing and files. Frequency of operation is $16 \mathrm{MHz}$. We use ATMEGA328 SMD IC for ARDUINO development board.

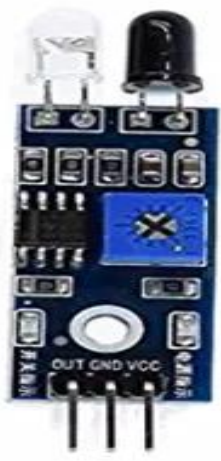

Fig. 5.IR sensor

For the identification of objects, infrarot sensor is used. We are tracking vehicle movement and pace on a high level in our proposed system for the operation of automobiles. IR with ground three pins, voltage, info. That's the microcontroller.

\section{E. Relay}

A relay is the electromagnetic instrument used for the load-to-microcontroller switch and interfacing module.. We used $5 \mathrm{~V}$ relay in our framework for switching on and off load pump engines. Of pumps from outside, we take $230 \mathrm{~V}$.

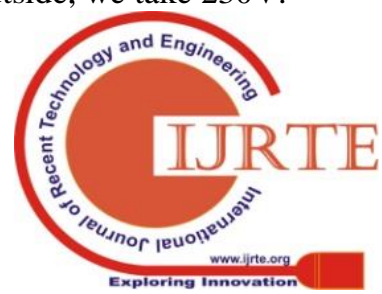


Relais operation mode is usually shut down. When a high-relay input is switched on a short circuit and a low-relay input is enabled.

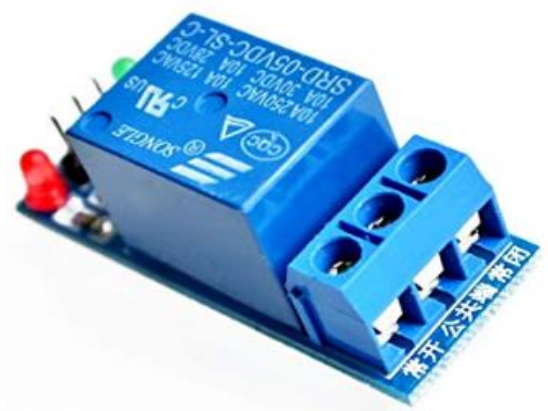

Fig. 6. Relay Module

\section{F. LDR Sensor}

The resistor based on light measures the intensity of light. The LDR module is translated into electrical quantities by light quality. This voltage includes analog pins for the micro controller. Input devices are activated by controller. The LDR modules ' functions in the project that are observed as low or high light concentrations depend on whether we assume the it is day or night

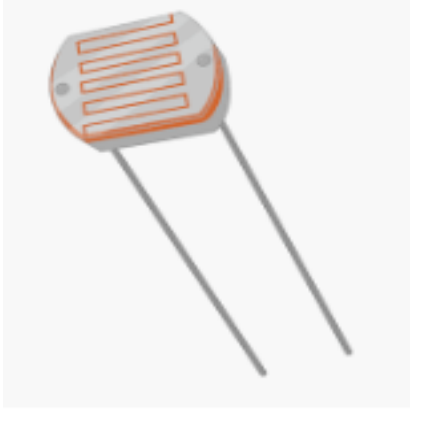

\section{LDR module}

\section{G. LED}

LED LIGHTS of $230 \mathrm{~V}$ are used as highway street light. Both LEDs for a brighter and dimer case are powered by a PWM technique. All are operated by microcontroller traic or relay.

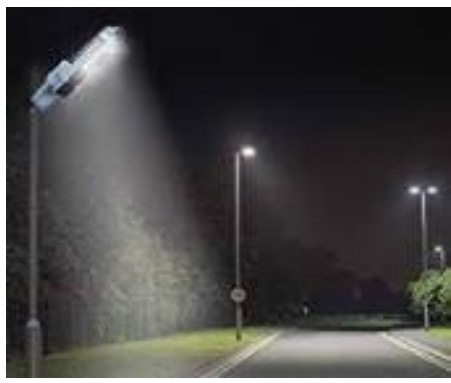

Fig. 7.Street light

\section{H. WI-FI Module}

Wireless communication is obligatory to transmit data from different places. One of the most advanced IOT wireless communications. The Cloud of Things. The IOT definition is achieved by way of a computer known as ESP8266. The frequency is controlled on a $5 \mathrm{GHz}$ wireless basis. Send and receive the data trough wirelessly by the sender and by the receiver. The modem voltage is $3.3 \mathrm{~V}$ and the power consumption is $100 \mathrm{~mA}$. The 2 GPIO pins hold 8 holes. It includes $512 \mathrm{~KB}$ of flash storage memory. The main role of IOT in the project is the sending of data to the ESP8266 module by the micro-controller. It sends moisture, temperature and light data to the local ESP 8266 server. When the same register has been accessed at the receiving end, the user will access data.

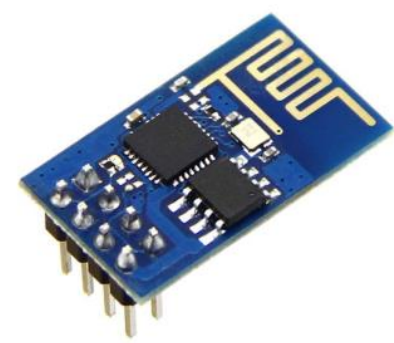

Fig. 8.ESP Module

\section{Software}

Both software and hardware are supplied by Embedded System. To develop the programming code, software is an important module. We have used ARDUINO IDE software for editing, compiling and dumping of c language in the application of proposed methodology. Before implementing a hardware simulation is an essential tool for virtually designing a project. To simulate the whole project, we used proteus software. Technology of Express $\mathrm{SCH}$ for constructing project schematic diagrams.

\section{RESULT AND DISCUSSION}

All input and output modules were interfaced successfully with the microscope. The controller has performed the results and performed them as required. In the LCD and IOT modules we got light and entity counts. Light automated monitoring dependent on LDR status was observed. Count and level of the detected automobile in display also.

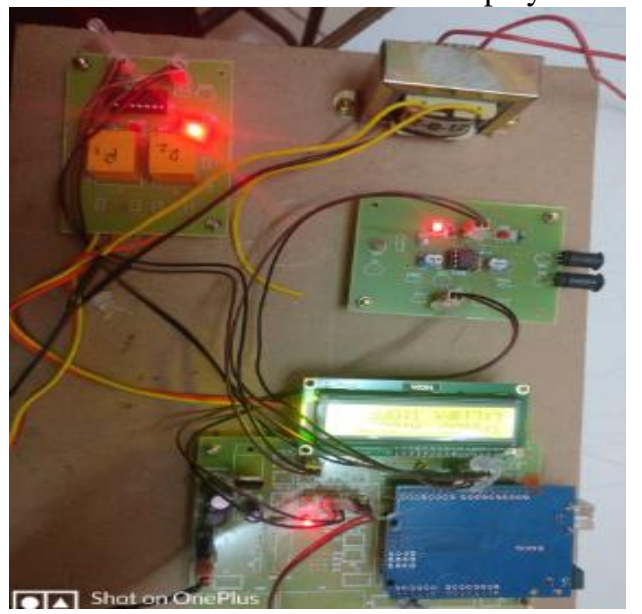

Fig. 9. Output Result1. Output figures is shows that vehicle count and speed of the vehicle in day and night mode. 




Fig. 10. Output Result2

\section{CONCLUSION}

The planned software has been developed for automatic street lighting and highway counting systems with all input sensors IR, Light Sensor and all power modules such as relay, LCD, LED and IOT, interfacing all the devices with ARDUINO microcontroller and integrated with ARDUINO IDE. Smart smart High-way street light infrastructure with low cost, fast access and automation is successfully implemented. We will add another wireless module, like the GSM modem, to light ON / OFF alerts directly for authorised persons in the further study of this project. For very fast and low power consumption we use very high concentration sensors.

\section{REFERENCES}

1. Archana. G, Aishwarya N, Anitha J "Intelligent Street Light System” International Journal of Recent Advances in Engineering \& Technology,

2. Vol-3, Issue-4, 2015

3. AkshayBalachandran, Murali Siva, V. Parthasarathi, Surya and Shriram K. Vasudevan "An Innovation in the Field of Street Lighting System with Cost and Energy Efficiency"Indian Journal of Science and Technology,Vol-8, August 2015

4. DeepanshuKhandelwal, Bijo M Thomas, KritikaMehndiratta, Nitin Kumar "Sensor Based Automatic Street Lighting system" International Journal of Education and Science Research Review Volume-2, Issue-2 April- 2015 .

5. IsahAbdulazeez Watson, OshomahAbdulaiBraimah, Alexander Omoregie " Design and Implementation of an Automatic Street Light Control System" International Journal of Emerging Technology and Advanced Engineering, Volume 5, Issue 3, March 2015 KapseSagar Sudhakar1, AbhaleAmol Anil2, Kudakechetan Ashok3, ShirsathShravan Bhaskar4 "Automatic Street Light Control System" International Journal of Emerging Technology and Advanced Engineering"'Volume 3, Issue 5, May 2013 Hachem, S., Teixeira, T., \& Issarny, V. (2011). Ontologies for the internet of things (pp. 1-6). New York: ACM.

6. Wan, J., Yan, H., Suo, H., \& Li, F. (2011). "Advances in cyber-physical systems research", KSII Transactions on Internet and Information Systems, 5(11), 1891-1908.

7. Tsai, C., Lai, C., \& Vasilakos, V. (2014). "Future internet of things Open issues and challenges". ACM/Springer Wireless Networks.

\section{AUTHORS PROFILE}

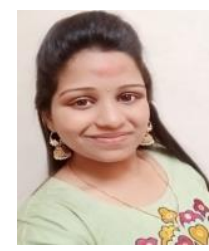

Vallala Alekya, Pursuing master of technology in Electronic Design Technology, S R Engineering College. Warangal, Telangana.

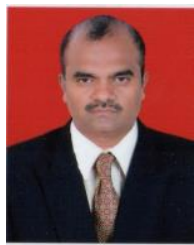

Dr. L. M. I. Leo Joseph working as Assistant Professor in department of Electronics and Communication Engineering, S R Engineering College, Warangal, Telangana. 